Papers in Evolutionary Economic Geography

$$
\text { \# } 17.05
$$

Institutional Change and Network Evolution: Explorative and Exploitative Tie Formations of Co-Inventors During the Dot-com Bubble in the Research Triangle Region

Max-Peter Menzel, Maryann P. Feldman, Tom Broekel

Utrecht University

Urban \& Regional research centre Utrecht 


\title{
Institutional Change and Network Evolution: Explorative and Exploitative Tie Formations of Co-Inventors During the Dot-com Bubble in the Research Triangle Region
}

\author{
Max-Peter Menzel*+, Maryann P. Feldman**, and Tom Broekel***
}

January 19, 2017

* max-peter.menzel@uni-bayreuth.de, Universität Bayreuth, Geographisches Institut, Universitätsstraße 30, D-95440 Bayreuth.

+ Corresponding Author

** maryann.feldman@unc.edu, University of North Carolina at Chapel Hill, Department of Public Policy, 209 Abernathy Hall, Chapel Hill, NC 27599-3435.

*** broekel@wigeo.uni-hannover.de, Leibnitz-Universität Hannover, Institut für Wirtschafts- und Kulturgeographie, Schneiderberg 50, 30167 Hannover

\begin{abstract}
We investigate how institutions impact tie formation. In doing so, we describe Venture Capital as institution that can direct firm strategies towards exploration or exploitation. These strategies are translated into tie formations: explorative tie formation produces structural holes as a source of "good ideas", exploitative tie formation closes structural holes to facilitate the mobilization of resources to put ideas into products. Using the example of co-inventors in ICT in the Research Triangle Park during the dot-com bubble, we expected explorative tie formation during the bubble and exploitative tie formations after its burst. Stochastic Actor Oriented Models did not clearly support our assumptions. We found that the emergence of venture capital lead to a large variance in connection patterns during the bubble, probably resulting from overlapping institutional effects. After the burst of the bubble, these incoherencies disappeared.
\end{abstract}

\section{Funding}

Max-Peter Menzel would like to thank the Department of Public Policy at UNC to be his host for this research and the DFG for the research grant ME 3703/1-1 that sponsored this research. 


\section{Introduction}

The quality and structure of networks are important to regional development. Moreover, regional networks are not static: a network structure that might be beneficial at one point in time may later inhibit change and contribute to a region's decline (GRABHER, 1993). The longitudinal development of regional networks is affected by endogenous network dynamics (FLEMING and FRENKEN, 2007; TER WAL, 2013b). However qualitative accounts like SAXENIAN's (1994) comparison of networks in the computer industries reveals institutional differences leading to heterogeneous network structures. Despite the consensus that institutional differences impact regional network structures, there is little examination of how institutions shape networks, despite regional policy emphasis on institutions (GRABHER, 1993).

Causality is difficult to disentangle when networks and institutions co-evolve. An evolutionary perspective requires an empirical case with both institutional and network change. Technology bubbles are associated with the emergence of new institutional forms, which is especially true for finance, with new institutions formed to direct funding towards new technologies PEREZ, 2009). Since the financial system impacts the evolution of industries (DOSI, 1990), major technological bubbles present opportunities for investigating how institutions impact the evolution of networks.

We investigate the dot-com bubble of the late-1990s - early 2000s. The emerging institution is venture capital (VC), which played an important role in the creation of the dot-com bubble as internet firms received a new form of financializing (PEREZ, 2009). With the burst of the dot-com bubble, however, VC capital inflows stopped and firms had to react to this altered condition. Thus, in addition to investigating how the emergence of this institution impacts connection behavior, we must also investigate what happens when this institution dramatically changes. We argue that VC, as an institution, altered the way that firms invent, and, accordingly, how inventors behave. Inventor behavior reflects firm strategies, since inventors are embedded in firm routines (DICKEN and MALMBERG, 2001). Our expectation for tie formation is based on OBSTFELD's (2005) distinction between sparse and dense networks. Accordingly, we expect that tie formation related to explorative strategies creates structural holes, while tie formation connected to exploitative strategies closes structural holes.

VC rewards firms that produce good ideas (HELLMANN and PURI, 2000). Accordingly, we expect firms to apply explorative strategies during the bubble. When financing withdraws firms need to generate 
income and switch to exploitative strategy, (MARCH, 1991). Thus the change from bubble to burst alters firm strategies, which impacts the way new ties are formed. During bubbles, new ties produce structural holes; new ties serve to close structural holes during bursts. To test our assumptions, we investigate the longitudinal development of networks using ICT inventor networks in the Research Triangle region of North Carolina (FELDMAN and LOWE, 2015). We apply SNIJDERS' (2001) Stochastic Actor Oriented Models (SAOM) to investigate the evolution of networks from 1991 until 2007.

The remainder of the paper is organized as follows. The next section provides a baseline model by describing how networks co-evolve with industries. The third section describes the connection between institutional change and major technology bubbles. The fourth section serves to define venture capital as an institution and describes how this institution favors explorative strategies. The fifth section translates explorative and exploitative firm strategies into network dynamics while the sixth section describes model and data. The seventh section provides the results. The eighth section reflects on measurements of institutional change, while the final section provides recommendations for further research.

\section{Evolution of Networks in Space}

When new industries emerge, firms experiment with technological approaches. TER WAL and BOSCHMA (2011) argue that emergence is shaped by unstable network patterns, formed by social and random contacts, and preferential attachment processes. Fragmentation creates uncertainty about the future direction of the trajectory. But over time, certain approaches become promising, while others are rejected. As a result, heterogeneity among firms declines as the trajectory becomes increasingly focused (DOSI, 1982; SUAREZ, 2004).

This evolution of network structure depends on the connecting strategy of actors. When faced with market uncertainties and unstable external conditions, firms apply an exploitative strategy that reinforce relations with existent partners. In contrast, when market conditions are favorable, firms focus on adopting new technologies, restructuring business processes, and applying explorative strategies to access novel information from new partners. TER WAL (2013b) finds triadic closure is a main driver of network evolution, which implies a closing of structural holes during times of exploration. 
To conclude, networks become less fragmented over time, less shaped by geographical proximity, and more strongly shaped by the particular dynamics of the industry or the field. Economic bubbles may cause deviations in the incremental co-evolution of networks and industries (PEREZ, 2009).

\section{Institutional Change and Major Technology Bubbles}

Economic bubbles are part of capitalist systems. PEREZ (2009, p. 780) defines technology bubbles, as "caused by the way the market economy absorbs successive technological revolutions". New technologies go through a phase of experimentation (ANDERSON and TUSHMAN, 1990). After the experimentation, a technological trajectory is established (DOSI, 1982). The decrease of technological risk then attracts resources from other sectors (STORPER and WALKER, 1989). Technology bubbles start when technological risks have been reduced.

The emergence of new technologies is related to the emergence of new forms of financing (PEREZ, 2009). The financial sector innovates to facilitate the transfer of resources into the new technology, which accelerates financial inflows driven by future expectations, rather than current earnings and profits. This disconnect new technology from the real economy, thereby producing financial risks. The connection between the new technology and new forms of financing are the basis for the bubble. The burst of a bubble is marked by a rapid withdrawal of money, resulting in bankruptcies and little entry (PEREZ, 2009).

The dot-com bubble provides an example. The foundation of the bubble started in 1994 with a rise in shares at the New York Stock Exchange for the first internet products; between 1997 and 2000 tech company stocks rose over 300\% (PEREZ, 2009). The dot-com bubble was driven by VC LERNER (2002) and started when technological risks decreased. VC created large financial inflows into ICT: profits were of less importance then future expectations. By financializing future expectations, VC was a crucial driver of the late 1990-early 2000 dot-com bubble (PEREZ, 2009). This next section describes VC as an institution that influences the economic behavior of firms. 


\section{Venture Capital as an Institution}

There are different definitions of institutions based on their ontology ( NORTH, 1990, 3; AMIN and THRIFT, 1995; NELSON, 1993; COOKE, 1992, HODGSON, 1998). What these definitions have in common is that institutions create expectations. Hence, BATHELT and GLÜCKLER (2014, p. 341) define institutions "as stabilizations of mutual expectations and correlated interaction". For VC to be defined as an institution it has to fulfill two requirements. First, VC organizations have to act in a particular and foreseeable way that creates expectations. Second, these expectations require the existence of a critical mass of VC firms to be relevant to affect the behavior of an entire industry.

We already described the strong growth of VC financing in from the mid-90s till 2000, which serves as an indicator that VC became sufficiently pervasive to create expectations and influence firm behaviors. Different forms of financing impact innovation and industry evolution as described by DOSI (1990), who distinguished between marked-based and credit-based financial systems, and argued that market-based financial systems allow for new firm formations. In contrast, credit-based systems favor diversification of existing firms. According to FLORIDA and KENNEY (1988, p. 120), "venture capital has given rise to a 'new model' of innovation which transcends the entrepreneurial versus corporate dichotomy. VC differs from established forms of financing and we can also expect newly institutionalized forms of financing to impact firm behavior. "

VC invests in sectors with fast firm growth (GOMPERS and LERNER, 2001) and selects firms according to particular criteria; for example, innovativeness (HELLMANN and PURI, 2000). Firms interested in VC financing adjust their behavior to conform to VC expectations: For example, when VC firms invest in firms that are innovators then firms have an incentive to innovate (PEREZ, 2009). In doing so, VC as an institution affects the behavior of firms in an industry.

MARCH (1991, p. 85) distinguishes between exploitation and exploration: "The essence of exploitation is the refinement and extension of existing competences, technologies, and paradigms. Its returns are positive, proximate, and predictable. The essence of exploration is experimentation with new alternatives. Its returns are uncertain, distant, and often negative" March argues that there are tradeoffs. Exploitative strategies are beneficial to generating short run profits. Long-term adaptability also requires exploration. 
The emergence of VC implies a temporal change in the environment of firms. VC favors explorative strategies. However, when VC withdraws this change of environment requires firms to improve their performance by shifting to exploitative strategies (March 1991).

From an analytical point of view, the connection between VC, high growth technology firms, and the notions of exploration and exploitation is not without problems. GUPTA et al. (2006), referring to marketable products, argued that exploration involves the production of new knowledge, while exploitation refines existing knowledge. In new technology sectors, firms produce new knowledge and this interpretation implies that firms have just one strategic option-exploration. For firms in our study, the product is primarily an idea, which also differ in their degree of novelty (NOOTEBOOM, 1999), implying that firms are heterogeneous and their strategies differ (NELSON and WINTER, 1982; TEECE et al., 1997).

The distinction between exploration and exploitation implies temporality. Exploitation generates gains in the short run, while gains in the long run are generated by exploration. For high tech firms with strong growth, we can therefore use the notions of exploration and exploitation to distinguish strategies for long-term future gains, or strategies to generate short-term gains. The exploration/exploitation dichotomy allows us to investigate differences in firm strategies in relation to both their particular environment as well as other firms. We expect that the emergence of VC, as an important form of investment, facilitates the adoption of explorative strategies in the late 1990s. With the burst of the bubble, the reduction of VC dependencies and the increasing importance of actual economic performance, exploitation strategies are more likely to be adopted. To conclude, we expect the phase before and after the bubble to differ significantly in terms of observed firm strategies.

\section{Explorative and Exploitative Connecting Strategies}

Firms apply explorative strategies to generate new ideas, with the intention of receiving VC and exploitative strategies in order to generate short term profits when facing the real economy. These strategies can be translated into knowledge sourcing and network positions. BURT, 1992) used the concept structural hole to describe network positions: If node $A$ is connected to B and C but B not to C,

there is a structural hole between A and C. The position at structural holes allows actors to combine different knowledge and to generate good ideas (KOGUT and ZANDER, 1992; MENZEL, 2015, 2015). 
BURT (2004) found that managers in a U.S. electronic company with group spanning ties not only have more ideas, but their ideas are also more likely to be identified as valuable. However, BURT (2004) found that astonishingly few of these ideas found their way into practice. This observation led OBSTFELD (2005) to argue that actors within sparse networks might have an action problem. The mobilization of good ideas is facilitated by structurally embedded positions common in dense networks. Accordingly, these networks are beneficial to put ideas into practice (UZZI, 1997; OBSTFELD, 2005). However, OBSTFELD (2005) argues that these networks have an idea problem: many links are redundant and there is little opportunity for new knowledge combinations.

Actors' positions in networks may change due to their own, as well as due to other actors' behavior (BAUM and MEZIAS, 1992). Creating a structurally embedded position requires a connecting behavior driven by triadic closure. Triadic closure implies that actors $A$ and $C$ are more likely to link if both are linked to actor B thereby closing the structural hole between them. In doing so, their relation shifts from an indirect one (through B) to a direct one. In contrast, to create a network position at structural holes requires a strategy that bridges distances to produce structural holes. For example, if node B is connected to A and C, B would not introduce A to C. Instead, it would connect to D. In doing so, B does not close the structural hole between A and C. Instead, B creates additional structural holes between D and $C$ as well as $D$ and $A$, and posits itself in the middle of them. These different strategies of creating and closing structural holes corresponds to explorative and exploitative firm strategies.

A number of studies compare explorative and exploitative network strategies. ROWLEY et al., 2000) used inter-firm alliances to investigate how firms form their networks in heterogeneous environments. They compare strong and weak ties by the quality of the alliance and denote weak as explorative ties and strong as exploitative ties. They found that firms in an industry, shaped by incremental and process innovation, apply exploitative strategies: their knowledge sourcing is characterized by strong ties and repeated tie formation. In contrast, firms in an industry with a radically changing and dynamic environment appear to benefit predominantly from weak ties.

LAZER and FRIEDMAN (2007) applied an agent base simulation to investigate the performance of exploitative and explorative network structures. Exploitative networks were defined by densely connected nodes; and explorative networks are networks with large path length and many structural holes. Their definition resembles our conceptualization. 
We derive two assumptions. First, we assume that the choice of explorative versus exploitative strategies depends on the particular environment in which a firm operates (ROWLEY et al., 2000). Second, we expected that explorative and exploitative strategies show distinct knowledge sourcing, and network behavior with explorative strategies corresponds to the creation of structural holes, while exploitative strategies corresponds to the closing of these holes.

\section{Method, Data and Indicators}

We follow TER WAL (2013a) in using patent co-inventors to construct knowledge networks. Using coinventor information instead of co-assignee information, provides a more complete picture of firms' knowledge sourcing and networking activities by considering internal as well as external knowledge sourcing. From a perspective of the firm as a "network within networks" (DICKEN and MALMBERG, 2001), links between inventors are indicators for these mechanisms.

Constructing networks from co-invention information is easy and commonly done in the literature (FLEMING et al., 2007; CASSI and PLUNKET, 2015); however analyzing them over time is more complex. Co-inventor information represents two-mode network data, as inventors are linked by a common event (the patent). The two-mode network data is usually projected to a binary network with inventors representing the nodes.1 Comparing networks over time requires unique inventor IDs. The procedure to generate unique inventors follows FLEMING and FRENKEN (2007), using last names, first names and middle initials and one additional non-name variable, such as zip code, assignee, or technology classification.

We focus on patents with at least one inventor in the Research Triangle Park (RTP) region, with the selection based on inventor's zip codes.2 To delimitate ICT, we use the scheme described in HALL et al. (2001).

\footnotetext{
${ }^{1}$ We refrained from a weighted projection, as we are primarily interested in the linking behavior and not so much in the importance of each link. Moreover, the later employed method (RSiena) currently still works best for binary networks.

${ }^{2}$ Zipcodes included in the analysis are: 27207, 27208, 27231, 27243, 27252, 27278, 27281, 27302, 27312, 27312, $27325,27330,27332,27332,27343,27344,27376,27424,27501,27502,27503,27504,27505,27507,27508$, $27509,27511,27513,27514,27516,27517,27517,27518,27519,27520,27521,27522,27523,27523,27524$, $27525,27526,27527,27529,27529,27536,27537,27540,27541,27542,27544,27544,27545,27546,27549$, $27551,27553,27553,27557,27559,27560,27562,27562,27562,27563,27565,27569,27572,27572,27573$,
} 
We assume that a link created by co-invention represents an interaction of five years: a link between two inventors starts four years prior to the observed patent application date. Following TER WAL (2013a), we construct our network using a five-year moving window: a network of a given year is based on all co-inventions of the preceding four years as well.

To detect potential shifts from exploration to exploitation behavior, we evaluate the individual behavior of actors by investigating the factors influencing their collaboration partner choice.

\section{A Stochastic Actor Oriented Model Approach}

BROEKEL et al. (2014) review methods for modelling link formation and dissolution at the individual actor level. The Stochastic Actor Oriented Models (SAOM) by SNIJDERS (2001) are particularly suitable for the identification of factors driving the evolution of networks (BROEKEL et al., 2014). SAOMs are based modelling actors' decisions (likelihoods) of creating, maintaining, or dissolving links at stochastically determined moments (SNIJDERS, 2001; TER WAL, 2013b; BROEKEL et al., 2014).In line with TER WAL (2013b) we restrict the analysis to all inventors that appear in at least two time periods in order to reduce the volatility of inventors entering and exiting the network. That is, we analyze the core of the network and the factors driving its dynamics.

There are three different types of effects. First, individual attributes relate to individual propensity of forming links. For instance, actors with superior knowledge might be particularly interesting collaboration partners and, hence, will be more frequently invited to collaborate. Effects at the dyad level impact the likelihood two specific actors form a link. In particular, homophily is a driver at the dyad level: more similar actors are more likely to interact. Effects of the structural network level correspond to network endogenous factors, which might be best understood as "self-reproducing network structures" (Broekel et al., 2014, 439). In our context, transitivity is such an effect at the structural network level.

$27574,27577,27581,27583,27586,27587,27589,27591,27592,27596,27597,27597,27601,27603,27604$, $27605,27606,27608,27608,27609,27610,27612,27613,27614,27615,27616,27617,27617,27701,27703$, $27704,27705,27707,27712,27713,27816,27850,27882,28315,28323,28326,28326,28327,28327,28334$, $28366,28373,28374,28387,28390,28394,27571,27607,27539,27526$ 
We estimate an individual SAOM for each year with respect to the network state from 5 years previous to ensure there is no overlap in the patents used to construct the two networks. The network is restricted to inventors assigned to at least one patent in both periods to reduce excessive fluctuations. The SAOM estimates parameter values that provide the best prediction of the empirical network evolution between the two time periods.

At the structural network level, we consider six different effects. Transitivity (TRANS) approximates the network's tendency to produce closed triplets of nodes. As this effect may show in different forms, we consider two alternative measures: number-of-distance-two-effect (DIST-2) and transitive ties (TRANSTIES). TRANS-TIES consider the number of links with length 2 between two inventors only if there exists at least one indirect path. DIST-2 counts the number of inventors which are indirectly linked with at least one intermediary. A positive coefficient of TRANS and TRANS-TIES corresponds to an exploitative strategy. DIST-2 obtains a positive coefficient in case inventors keep their distance to other inventors and do not establish densely linked groups, indicating explorative linking behavior.

Three structural variables serve as controls. Preferential attachment (PREF), a frequent driver of network evolution implies that nodes will have a tendency to first link to nodes that already have a great number of linkages (BARABÁSI and ALBERT, 1999). The same applies to the measure of assortative mixing (ASSORT), which is included in order to control for the opposite effect of nodes linking to other nodes of similar degree (NEWMAN, 2003). A density effect (DENSITY) corresponds to the general tendency of nodes to have ties. We include two variables that grasp knowledge and network dynamics using only co-inventor relations. Organizational proximity is measured by the variable ORGA, which is "1" if two inventors have the same assignee (and hence work for the same organization) and " 0 " otherwise. For the measurement of cognitive proximity (COGN), we follow the literature and make use of the USPC classification and the classes assigned to each patent (BRESCHI et al., 2003). We first count the number of occurrences of one-digit patent classes on each inventor's patents up until the beginning of the focal time period ( $t-5)$. Next, the measure of cognitive proximity is estimated by the cosine similarity between the vectors of patent class occurrences for each inventor pair.3 For both dyad level variables, a positive coefficient indicates a higher likelihood of link formation since actors are either cognitively or organizationally proximate; this thus corresponds to a rather exploitative collaboration

${ }^{3}$ We also experimented with alternative measurement approaches. For instance, we used different levels of patent class disaggregation. We also measured cognitive proximity by counting the number of patent classes (at different levels of disaggregation) they have in common. However, the cosine index approach provided the most stable and empirically reliable results. 
and networking strategy. To control for heterogeneity among actors, we include two variables at the node level. The "age" of an inventor (AGE), which is approximated by the time since an inventors' first patent application. Secondly, the size (SIZE) of an inventor captures the sum of patents assigned to this inventor through the year of observation.

\section{Longitudinal Development of Co-Inventor Networks in the Research Triangle}

Research Triangle Park (RTP) in North Carolina is located near the universities of Chapel Hill, Durham and Raleigh, which form the points of the triangular shaped region. The RTP was intended to contribute to the economic restructuring of the economy of North Carolina, which was previously dominated by textile, furniture and tobacco (LINK and SCOTT, 2003). The RTP started to flourish in 1965 when IBM established a major research center. Burroughs Wellcome, a UK pharmaceutical firm, added industry diversity to the RTP region with a large-scale research facility in 1983 . These two facilities define the prevalent industrial sectors. While the RTP started as an exemplary satellite platform district (MARKUSEN, 1996), entry of entrepreneurial firms (given the inevitable mergers, acquisitions, layoffs and closures of large firms) created a vibrant entrepreneurial economy in the surrounding Research Triangle Region (AVNIMELECH and FELDMAN, 2010). Our database consists of 25,349 patents with at least one inventor located in the RTP area. Table 1 describes the number of patents and inventors in more detail. The number of patents in life science and ICT reflect the industrial focus of the RTP. Table 1 also describes the number of inventors in the respective fields. The larger share of inventors in ICT reflects the larger numbers of patent in this field.

\begin{tabular}{|c|c|c|c|c|c|}
\hline & \multirow[t]{2}{*}{ Patents } & \multirow[t]{2}{*}{ Inventors } & \multicolumn{3}{|c|}{ Located in } \\
\hline & & & RTP & USA & World \\
\hline Life Science & 7.461 & 9.789 & 4.152 & 4.553 & 1.084 \\
\hline ICT & 13.309 & 14.497 & 6.964 & 6.396 & 1.137 \\
\hline Other & 4.559 & 6.097 & 3042 & 2.852 & 232 \\
\hline Total & 25.349 & 30.127 & 14112 & 13754 & 2453 \\
\hline
\end{tabular}

Table 1: Patents and Inventors 
We focus our analysis on the ICT sector; this is the largest employment sector in the region and most affected by the bubble. The purpose - to develop technologies like computer chips and the internet (BRESNAHAN and TRAJTENBERG, 1995) - make it important. Additionally, the ICT spans standard industry classification schemes (CORROCHER et al., 2007), and is shaped by fast innovation cycles (CHRISTENSEN, 1997). These conditions result in organizational forms that rely on projects (WHITLEY, 2006) and depend extensively on localized externalities (BOSCHMA and WETERINGS, 2005). The industry is known for having pervasive regional networks (SAXENIAN, 1994, BUENSTORF and FORNAHL, 2009).

\section{Temporal Development of the RTP Inventor Network}

Figure 1 illustrates the temporal development of patents and inventors in the RTP area from the mid1960s until 2007. The graph shows a slower early development for ICT, but stronger growth starting from the mid-1990s. The number of ICT patents peaked in 2000. After an initial downturn in patents after the burst of the bubble, the number of patents with RTP inventors started to grow. The strong growth of ICT compared to other patents shows that the ICT sector was indeed affected by the bubble.

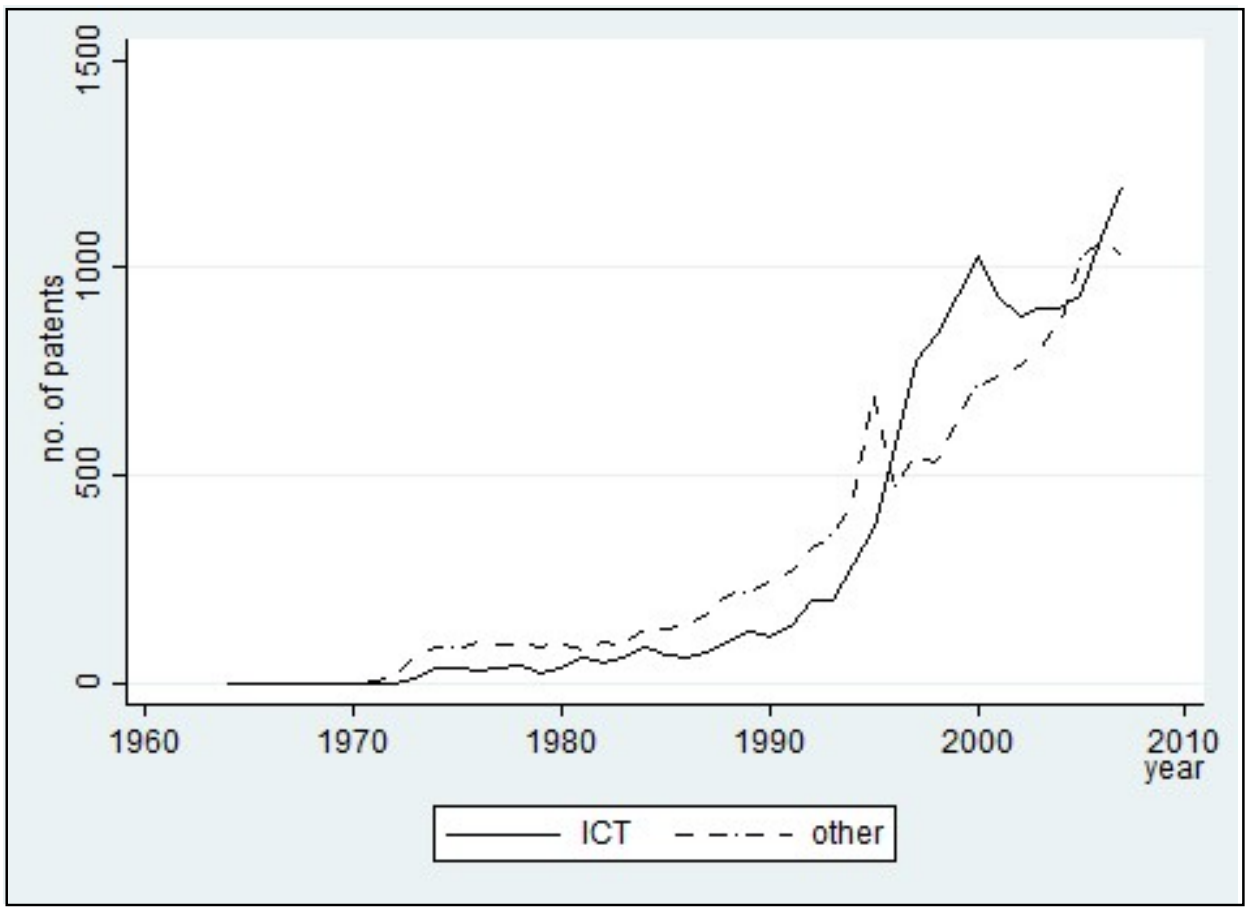

Figure 1: Development of ICT and all other Patents in RTP 
We hypothesized that the institutional change induced by the rise of $\mathrm{VC}$ resulted in changing connection strategies, which could be depicted by changes in network structure. We also expected a change in connecting behavior around the mid-1990s, when VC became a pervasive form of financing, and a change with the burst of the bubble in 2000 .

We cannot present all these individual models' results due to space limitations. Instead, we show results of the first SAOM in Table 2 and present the parameter obtained in the other SAOMs. We restrict the presentation to those variables that allow for inference about exploitation or explorative linking behavior, i.e. TRANS, TRANS-TIES, DIST-2 and ORGA.

Table 2 shows the results for the network evolution from the year 1991 to 1996 . All convergence t-ratios are below the 0.1 limit and, hence, we may take a look at the parameter and p-values. Of all variables, only TRANS and TRANS-TIES gain positive and significant ( 0.5 significance level) coefficients. This suggests that the network evolution is primarily driven by transitivity, indicating a rather exploitative networking behavior.

\begin{tabular}{|r|rrrr|}
\hline Variables & Parameter & P-values & $\begin{array}{r}\text { Standard } \\
\text { Error }\end{array}$ & $\begin{array}{r}\text { Convergence } \\
\text { t-ratio }\end{array}$ \\
\hline TRANS & 1.192 & 0.032 & 0.554 & 0.060 \\
TRANS-TIES & 0.721 & 0.016 & 0.300 & 0.042 \\
DIST 2 & 0.188 & 0.645 & 0.407 & 0.058 \\
ORGA & 1.755 & 0.141 & 1.193 & 0.021 \\
PREFE & 0.775 & 0.934 & 9.298 & 0.081 \\
ASSORT & -0.579 & 0.749 & 1.814 & 0.057 \\
DENSITY (degree) & -2.654 & 0.779 & 71.96 & 0.043 \\
COGN & -0.260 & 0.860 & 1.472 & 0.027 \\
AGE & -0.028 & 0.461 & 0.038 & 0.023 \\
SIZE & 0.010 & 0.965 & 0.222 & 0.065 \\
\hline
\end{tabular}

Table 2: The Co-inventor Network from 1991-1996

The size of the sample allows for a SAOM-Analysis from 1996. Figure 2 describes the structure of the network over time. The solid black line represents the parameter values of a factor obtained in the SAOMs estimated for each year, while the green area represents the confidence interval. TRANS is significantly larger than expected from a random network for most of the time (the lower and upper 
bound of the confidence interval being larger than zero, indicated by red line) and continually decreasing. As a result, the indicator is slightly larger before the bubble. However, we expected a more pronounced difference. The Figure also shows that the variance of the parameter became smaller after the bubble. This change indicates a slightly larger ambiguity of institutional effects during the bubble than after its burst.

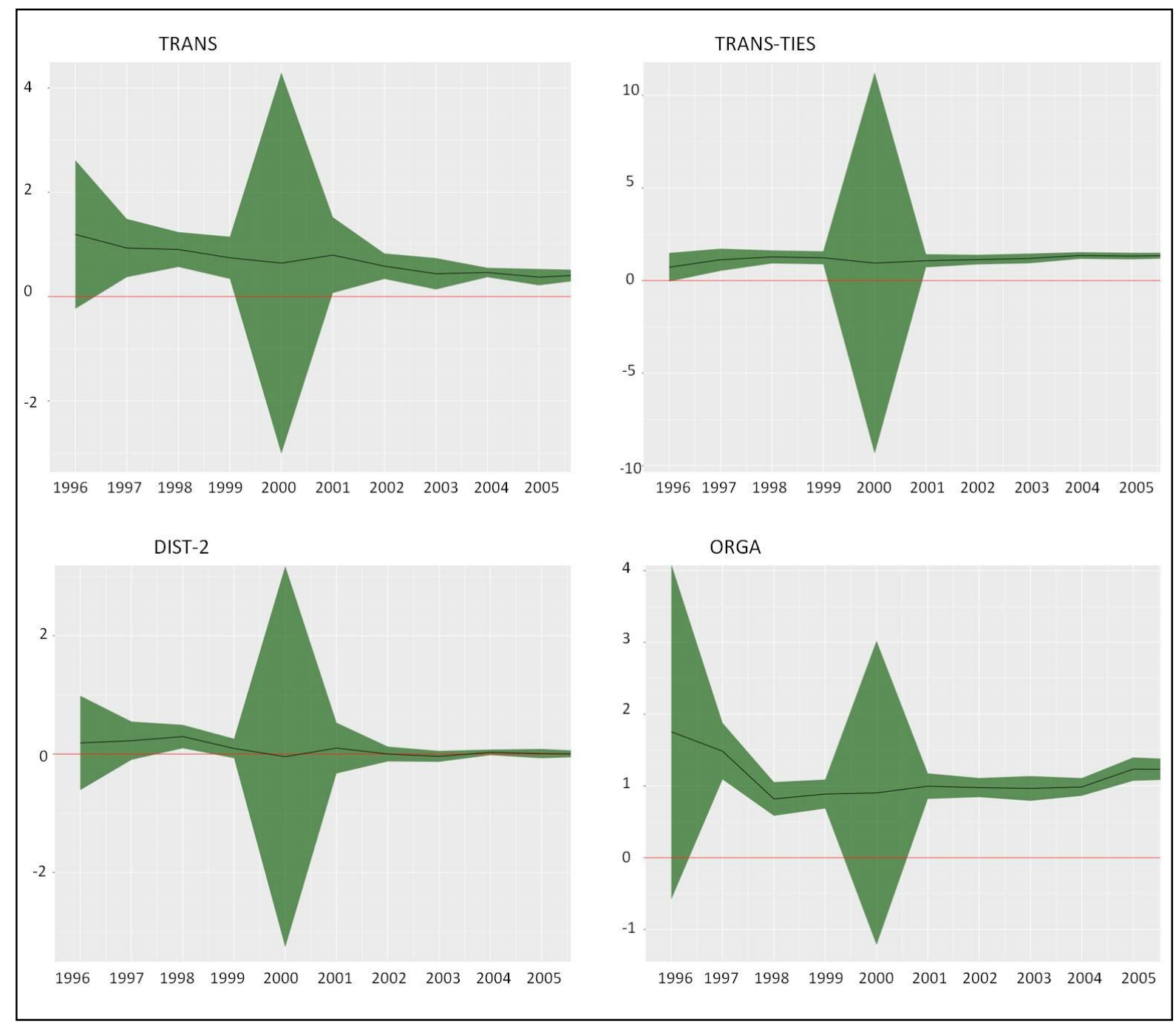

Figure 2: Network Structure over Time

A remarkable change in this pattern takes place during the burst of the bubble, when the confidence interval expands. During the burst of the bubble, connecting behavior was random: firms either formed many or nearly no embedded ties. Neither endogenous network dynamics nor external effects (like institutions) seem to guide the direction of the network. This large variance indicates that the burst of 
the bubble not only corresponded to a withdrawal of capital, but also corresponded to the withdrawal of institutions, resulting in uncertainty about appropriate connecting behavior.

TRANS-TIES is larger than expected from a random network and is remarkably stable over time. The confidence intervals widen in 2000, when the bubble burst. Yet, after the burst these intervals return to approximately the same width as they were before the burst.

In contrast to TRANS and TRANS-TIES, DIST-2 captures the relevance of network distance between partners. The parameter shows a similar development as those of TRANS and TRANS-TIES. There is no indication of a dramatic change in or after the year 2000. For most of the time, DIST-2 exhibits a value as expected from a random network. Only in 1998, it is significantly larger than expected from a random network. Comparable to TRANS, variance decreased, especially after the bubble.

The variable ORGA captures the likelihood of inventors linking to other inventors in their own firm. We find no clear indications for our hypothesis that ORGA is smaller before and larger after the burst of the bubble. Similar to the other variables, we found an enormous increase in variance when the bubble burst. Similar to TRANS and DIST-2, the confidence interval was slightly larger during the bubble than after its burst.

To conclude, Figure 2 gives at most weak support for our argument of changing patterns of tie formation before and after the burst of the bubble. Actually, the only result that supports our assumption is the significantly positive value for DIST-2 in the year 1998. It rather appears to be the case that the same forces drive the network evolution before and after the burst of the bubble, whereby their impacts become somewhat more significant (through narrowing of confidence intervals). The burst marks an interruption with evolutionary patterns becoming more or less random.

\section{The Structure of the Main Component}

If the rise of VC influences firm behavior, these effects should be more pronounced for inventions related to the internet, an area primarily supported by VC. We therefore extend the above analysis by focusing on the core of the network. The dominant USPTO class in the network's main component was 370 from 1992 until 1999 and 709 from 2000 to 2006. USPTO class 370 describes "Multiplex Communications" and class 709 includes "Electrical computers and digital processing systems: 
multicomputer data transferring". Both patent classes are core classes of internet related innovations (WAGNER and COCKBURN, 2010). Accordingly, internet related technologies are at the network's core.

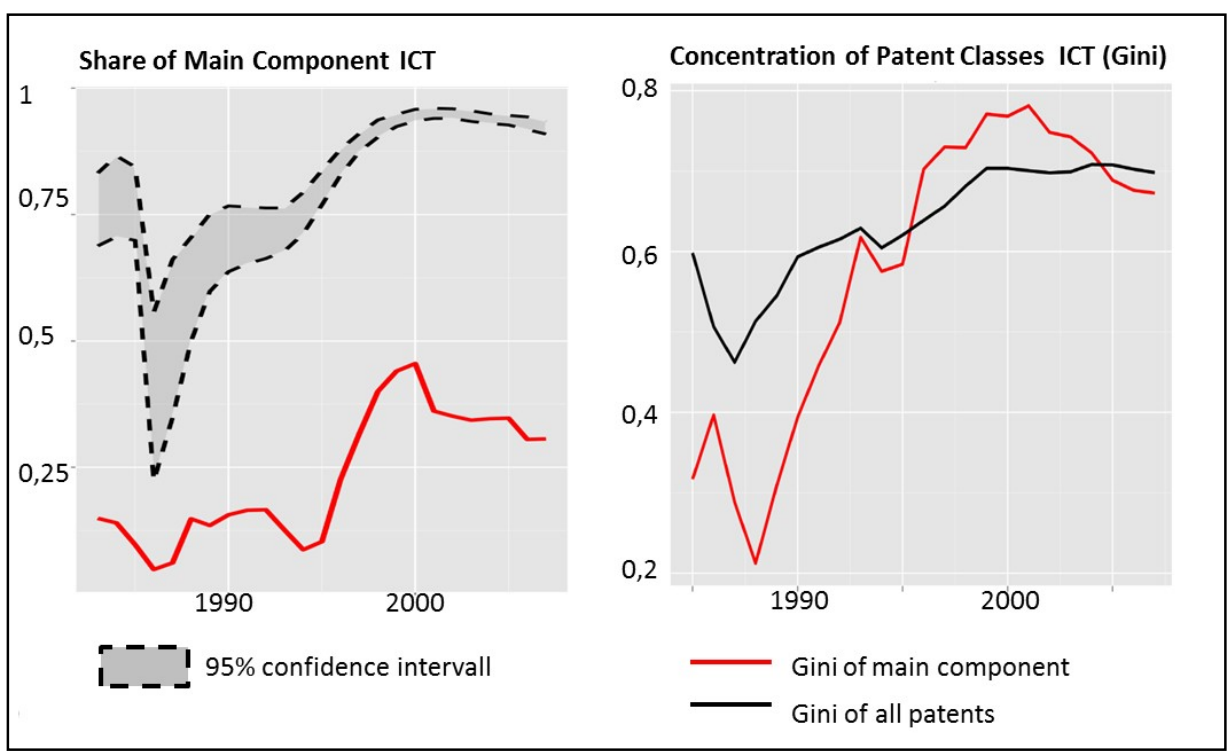

Figure 3: Description of the Main Component

Figure 3 describes the size of the main component and compares the Gini-coefficient for patent classes in the main component with the complete sample. The share of the main component increases from 1996 onward and peaked in 2000, with nearly 50\% of all ICT inventors. After 2000, the share of the main component decreases. Figure 3 shows that the Gini-coefficient of technology concentration in the main component was smaller than the Gini-coefficient for all ICT-patens in the 1990s, indicating more diverse main component. This changed from 1996 and since 1996, the main component became technologically more specialized than the remaining network. This specialization increased until 2001 and then decreased.

This observation suggests that the growth of the network's main component was fueled by financial flows into internet related innovations. However, despite its growth, the main component is still smaller than in comparable random networks suggesting that there still remains significant potential for establishing direct and indirect relations.

Figure 4 describes the development of TRANS, TRANS-TIES, DIST-2 and ORGA in the main component. The analysis starts in 1997 as the size of the main component is smaller than the whole network preventing analyses of previous years. The variables' parameters show different patterns in the main 
component than in the entire network. With the exception of TRANS-TIES, all variables show considerably larger variance during the bubble than afterwards. TRANS-TIES seems to capture a general endogenous network dynamic that does not seem to be affected by disruptive changes in the external environment. In contrast to the results for the full network, the variances during the bubble (pre 1999) resemble the variances observed during the burst of the bubble (1999-2001).

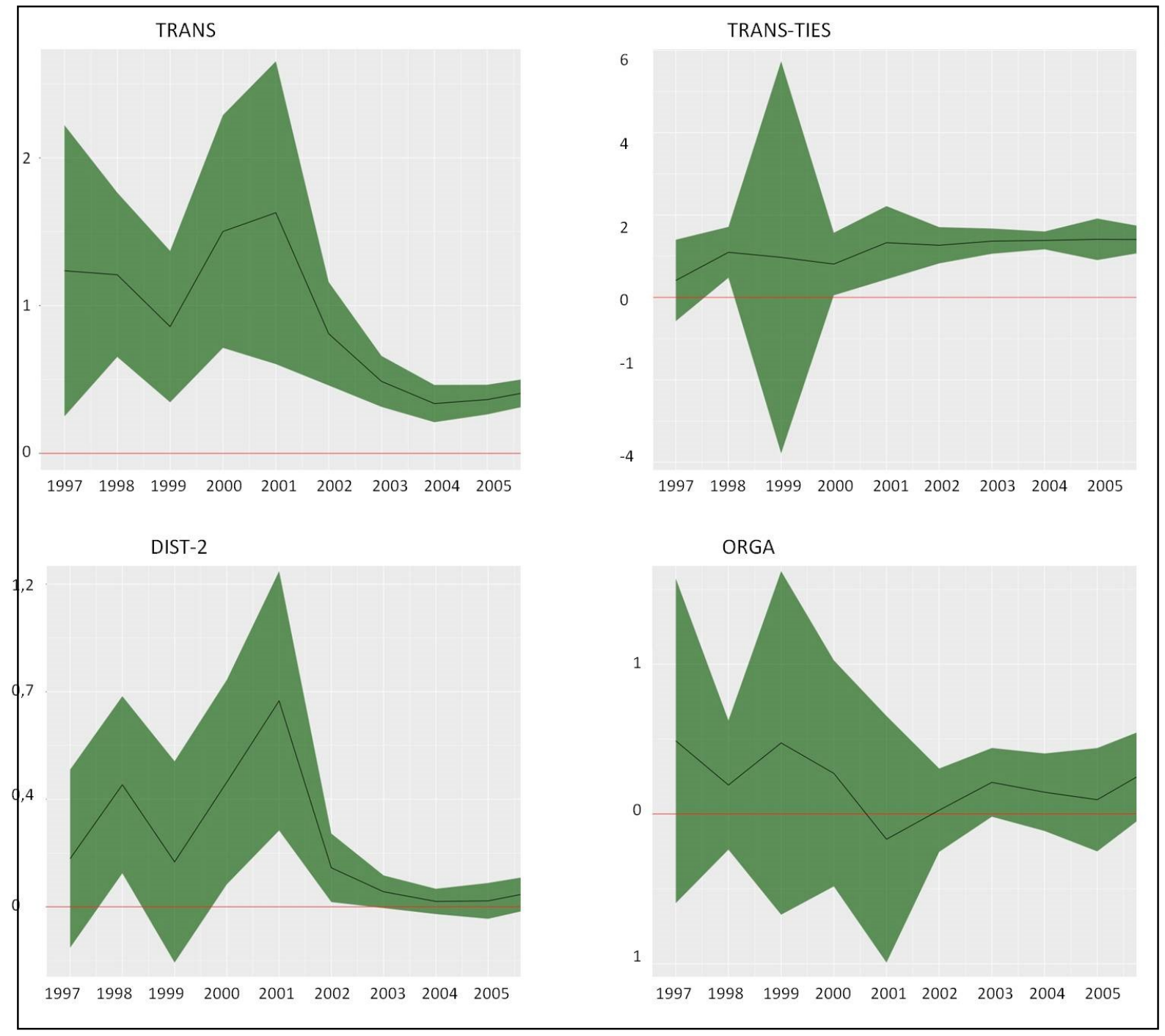

Figure 4: Longitudinal Development of the Main Component

DIST-2's parameter shows another interesting pattern, which differs from the entire network. DIST-2 is considerably larger in 1998 and 2000 and also significantly larger than the value that can be expected for a random network during the bubble. Moreover, in contrast to its development in the complete 
network, its values growth up to the year 2001. After the burst, its value becomes insignificant. Accordingly, inventors followed rather explorative strategies, which correspond to the type of behavior supported by VC, for most of the bubble phase.

Astonishingly, DIST-2 obtains its largest value in 2001, when the bubble already burst. It might be that the withdrawal of VC increased scarcity of resources, which led to competition for the remaining VC, incentivizing explorative knowledge sourcing behavior. Hence, this observation resembles a sailings ship effect, which got its name from the observation that innovation in sailing ships increased with the emergence of steamships (GRAHAM, 1956). Yet, these innovations took place in an inferior trajectory and did not prevent loss of market share and bankruptcy. In case of DIST-2, this effect might result in a delayed adjustment of the connection behavior.

Compared to the entire network, the analysis of the main component gave slightly stronger support for our hypothesis of changing knowledge networking behavior: the parameter of DIST-2 indicates a rather explorative networking behavior during the bubble and its burst, which disappears afterwards. The effect is much more pronounced in the main component than in the complete network, which suggest the presence of diverse forms of tie formation in the complete network and its main component. This fits to the observation that the latter is stronger focused on internet related technologies that also received the largest share of VC support.

\section{Connecting Behavior during Institutional Incoherencies}

We found no support for our hypotheses. One clear pattern we found from a micro perspective was the larger parameter variance before the bubble in comparison to after the bubble. This particularly applies to the parameters estimated for the main component. This section tries to interpret this change in variance.

The width of the confidence intervals indicates the parameters' variance. As institutions guide actions, variance indicates the quality of this guidance. If variance is small, institutions guide actions towards "stabilizations of mutual expectations and correlated interactions" (BATHELT and COHENDET, 2014, 341). In turn, a large variance would indicate either weak institutional guidance or behavior that is guided by overlapping and ambiguous institutions. While the indicators show the direction of 
institutional change, the confidence interval demonstrates the quality and strength of institutional effects.

The larger variance during (rather than after) the bubble might therefore point to a misconception of institutions. We assumed that institutions lead to correlated behavior of all actors. However, VC as a new institution seemed to only affect particular actors and not others. As a result, the emergence of VC did not lead to a homogenous and continual institutional change. Instead, some firms adjusted to the new institution, while others did not. Accordingly, the large variance might show the existence of overlapping institutions of corporate financing that impacted actors in different ways and to different extents.

PECK and THEODORE (2007) pointed out that firm behavior is the result of different and sometimes opposing institutions within the same institutional system. While the original Varieties of Capitalism approach, developed by HALL and SOSKICE (2001), argued that institutions need to be coherent and complementary for economic growth, SCHRÖDER and VOELZKOW (2016, p. 14) argued that institutions can diverge from the national model as "productive incoherencies" can be beneficial for firm growth. In doing so, they acknowledge that firms are affected by different and sometimes opposing institutions, which allows a variety of complementary firm behaviors. When VC represents an institutional incoherency, it would result in firm behavior that deviates from a dominant model. Such a deviation would be indicated by a larger variance found during the bubble.

Following this line of argumentation, the decrease in variance after the bubble would demonstrate that this incoherency disappears after the burst of the bubble. Two reasons may be responsible: the withdrawal of VC, and the alignment to established forms of corporate financing. We already described the withdrawal of VC after the burst of the bubble. Figure 5 describes the strategies of VC firms over time. It distinguishes between four forms of VC investments: Seed investment (firm with a concept or a product under development), early stage investment (product in testing or pilot production), expansion stage (product of service commercially available), and later stage (firm is generating ongoing revenue and might be profitable). Figure 6 shows that with the burst of the bubble the quality of VC investment changed. Seed investment which finances early ideas nearly disappeared after the bubble. In contrast, later stage investment, which finances already well performing firms, had the largest share in the postbubble phase. The influence of VC was not only weaker after the bubble. It also changed the type of firms it financed and, in so doing, alters the incentive structure. The decreasing amount of VC finance in 
connection with its adaption to established forms result in smaller institutional incoherencies and, accordingly, in smaller variance and smaller deviations in connection behavior.

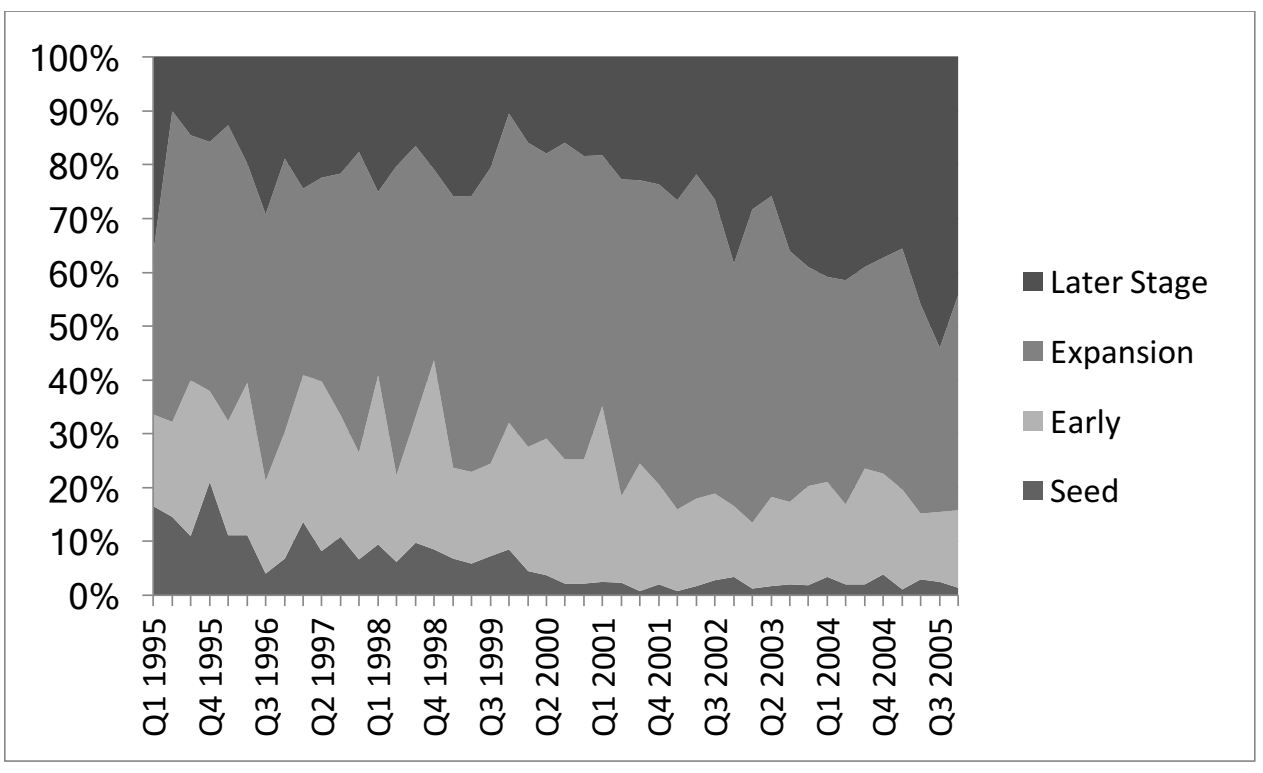

Figure 5: VC Investment regarding Stage of Development over Time (own calculations, data from www.pwcmoneytree.com, accessed May 19th 2016)

\section{Conclusion}

This paper analyzed the longitudinal development of inventor networks in the Research Triangle Park during the dot-com bubble as well as its burst. We used the phases of bubble and burst to investigate how the emergence, and disappearance, of a new institutional environment affects tie formation and network evolution. Using the example of $V C$ as new financial institution, we investigated how this institution guided financial flows into firms. In so doing, VC changed the incentive structure for firms.

As a reaction to this changed environment, we expected firms to adopt explorative strategies to generate "good ideas" (BURT, 2004) in order to receive VC. When VC was withdrawn, we expected a turn towards the use of exploitative strategies. We also expected that these changing firm strategies would be visible by tie formations by inventors. We connected explorative and exploitative strategies with respective forms of tie formations: explorative tie formations create structural holes, while exploitative tie formations close triads. We used stochastic actor oriented modelling to investigate if 
explorative ties are prevalent before the bubble while exploitative ties are prevalent after the burst of the bubble. The results demonstrate the appropriateness of this approach.

The results did not show a fundamental change towards explorative or exploitative tie formations. Indeed, the results illustrated how endogenous network dynamics like triadic closure drove network evolution (TER WAL, 2013b). We found a larger variance during the bubble than afterwards, indicating a larger diversity of connection strategies during than after the bubble especially in the main component. Therefore, we found some indirect support of our assumption that institutional changes affect connecting behavior and network evolution.

Yet, the large variance indicates that we might have incorrectly conceptualized institutional change, making it difficult to detect. We expected a homogenous and continuous institutional change towards a VC dominated financing system during the bubble. The large heterogeneity during the bubble might result from an institutional incoherency (SCHRÖDER and VOELZKOW, 2016), i.e., the parallel existence of an established system of corporate financing as well as a new system dominated by VC. Furthermore, the way we conceptualized VC seemed to describe only a certain phase. VC firms aligned their investment strategies towards more conservative forms of corporate finance after the bubble. While we expected VC to change finance, VC itself changed. The change of institutions as well as the parallel existence of different institutions shows the complexity in investigating institutional effects on network evolution.

There are recent contributions that intend to integrate institutions in evolutionary perspectives on regional developments (MENZEL and KAMMER, 2012; BOSCHMA and CAPONE, 2015, HASSINK et al., 2014). These studies conceptualized institutions as homogeneously affecting firm behavior, which was also our starting point. Our results, however, would support recent finding of the varieties of capitalism approach (SCHRÖDER and VOELZKOW, 2016): institutions can be incoherent and affect different actors in different ways. Therefore, including institutions into evolutionary approaches might consider that institutions change the same ways as the conceptions of firms and networks have changed previously. While the heterogeneity of firms has long been ignored, evolutionary approaches emphasize the difference between firms (BOSCHMA and TER WAL, 2007). These differences are important to understanding regional development (BOSCHMA and WENTING, 2007; KLEPPER, 2007). In the same vein, regional networks have long been considered as pervasive and uniformly open to all actors in the region (SAXENIAN, 1994). Social network analyses showed that networks are highly selective, integrating 
certain actors while excluding others (GIULIANI, 2007). Our results point out that institutions exhibit comparable degrees of complexity.

\section{References}

AMIN A. and THRIFT N. (1995) Globalisation, institutional thickness and the local economy, in HEALEY P., CAMERON S., DAVOUDI S., GRAHAM S. and MADANI-POUR A. (Eds) Managing cities: The new urban context, pp. 91-108. Wiley.

ANDERSON P. and TUSHMAN M. L. (1990) Technological Discontinuities and Dominant Designs - A Cyclical Model of Technological-Change, Administrative Science Quarterly 35, 604-33.

AVNIMELECH G. and FELDMAN M. (2010) Regional Corporate Spawning and the Role of Homegrown Companies, Review of Policy Research 27, 475-89.

BARABÁSI A.-L. and ALBERT R. (1999) Emergence of scaling in random networks, Science 286, 509-12.

BATHELT H. and COHENDET P. (2014) The creation of knowledge: local building, global accessing and economic development: toward an agenda, Journal of Economic Geography 14, 869-82.

BOSCHMA R. and CAPONE G. (2015) Institutions and diversification: Related versus unrelated diversification in a varieties of capitalism framework, Research Policy 44, 1902-14.

BOSCHMA R. and WENTING R. (2007) The spatial evolution of the British automobile industry: Does location matter?, Industrial and Corporate Change 16, 213-38.

BOSCHMA R. A. and WETERINGS A. B. R. (2005) The effect of regional differences on the performance of software firms in the Netherlands, Journal of Economic Geography 5, 567-88.

BRESCHI S., LISSONI F. and MALERBA F. (2003) Knowledge-relatedness in firm technological diversification, Research Policy 32, 69-87.

BROEKEL T., BALLAND P.A., BURGER M. and VAN OORT F. (2014) Modeling knowledge networks in economic geography: a discussion of four methods, The annals of regional science 53, 423-52. 
BUENSTORF G. and FORNAHL D. (2009) B2C-bubble to cluster: the dot-com boom, spin-off entrepreneurship, and regional agglomeration, Journal of Evolutionary Economics 19, 349-78.

BURT R. S. (1992) Structural Holes. Harvard University Press, Cambridge MA.

BURT R. S. (2004) Structural holes and good ideas, American Journal of Sociology 110, 349-99.

CASSI L. and PLUNKET A. (2015) Research collaboration in co-inventor networks: combining closure, bridging and proximities, Regional Studies 49, 936-54.

CHRISTENSEN C. M. (1997) The Innovator's Dilemma: When New Technologies Cause Great Firms to Fail. Harvard Business Press.

COOKE P. (1992) Regional Innovation Systems - Competitive Regulation in the New Europe, Geoforum 23, 365-82.

CORROCHER N., MALERBA F. and MONTOBBIO F. (2007) Schumpeterian patterns of innovative activity in the ICT field, Research Policy 36, 418-32.

DICKEN P. and MALMBERG A. (2001) Firms in Territories: A Relational Perspective, Economic Geography 77, 345-63.

DOSI G. (1982) Technological Paradigms and Technological Trajectories, Research Policy 11, 147-62.

DOSI G. (1990) Finance, innovation and industrial change, Journal of Economic Behavior \& Organization 13, 299-319.

FELDMAN M. and LOWE N. (2015) Triangulating regional economies: Realizing the promise of digital data, Research Policy http://dx.doi.org/10.1016/j.respol.2015.01.015.

FLEMING L. and FRENKEN K. (2007) The evolution of inventor networks in the Silicon Valley and Boston regions, Advances in Complex Systems 10, 53-71.

FLEMING L., KING III C. and JUDA A. I. (2007) Small worlds and regional innovation, Organization Science $18,938-54$.

FLORIDA R. L. and KENNEY M. (1988) Venture capital, high technology and regional development*, Regional Studies 22, 33-48. 
GIULIANI E. (2007) The selective nature of knowledge networks in clusters: evidence from the wine industry, Journal of Economic Geography 7, 139-68.

GOMPERS P. and LERNER J. (2001) The venture capital revolution, The Journal of Economic Perspectives $15,145-68$.

GRABHER G. (1993) The Weakness of Strong Ties. The Lock-in of Regional Development in the Ruhr Area, in GRABHER G. (Ed) The Embedded Firm, pp. 255-77. Routledge, London.

GRAHAM G. S. (1956) The Ascendancy of the Sailing Ship 1850-85, The Economic History Review 9, 7488.

GUPTA A. K., SMITH K. G. and SHALLEY C. E. (2006) The interplay between exploration and exploitation, Academy of Management Journal 49, 693-706.

HALL B. H., JAFFE A. B. and TRAJTENBERG M. (2001) The NBER patent citations data file: lessons, insights and methodological tools, NBER Working Paper Series, p. 74, Cambridge, MA.

HALL P. and SOSKICE D. (Eds) (2001) Varieties of capitalism: the institutional foundations of comparative advantage. Oxford University Press, Oxford.

HASSINK R., KLAERDING C. and MARQUES P. (2014) Advancing evolutionary economic geography by engaged pluralism, Regional Studies 48, 1295-307.

HELLMANN T. and PURI M. (2000) The interaction between product market and financing strategy: The role of venture capital, Review of Financial studies 13, 959-84.

HODGSON G. M. (1998) The approach of institutional economics, Journal of Economic Literature 36, 166-92.

KLEPPER S. (2007) Disagreements, spinoffs, and the evolution of Detroit as the capital of the US automobile industry, Management Science 53, 616-31.

KOGUT B. and ZANDER U. (1992) Knowledge of the Firm, Combinative Capabilities, and the Replication of Technology, Organization Science 3, 383-97.

LAZER D. and FRIEDMAN A. (2007) The network structure of exploration and exploitation, Administrative Science Quarterly 52, 667-94. 
LERNER J. (2002) Boom and bust in the venture capital industry and the impact on innovation.

LINK A. N. and SCOTT J. T. (2003) The growth of Research Triangle Park, Small Business Economics 20, 167-75.

MARCH J. G. (1991) Exploration and exploitation in organizational learning, Organization Science 2, 7187.

MARKUSEN A. (1996) Sticky places in slippery space: A typology of industrial districts, Economic Geography 72, 293-313.

MENZEL M.-P. (2015) Interrelating Dynamic Proximities by Bridging, Reducing and Producing Distances, Regional Studies 49, 1892-907.

MENZEL M.-P. and KAMMER J. (2012) Industry Evolution in Varieties of Capitalism: a Survival Analysis on Wind Turbine Producers in Denmark and the USA, Papers in Evolutionary Economic Geography (PEEG) 12,34 .

NELSON R. R. (Ed) (1993) National Innotation Systems . A Comparative Analysis. Oxford University Press, Oxford.

NELSON R. R. and WINTER S. G. (1982) An Evolutionary Theory of Technical Change. Harvard University Press, Cambridge.

NEWMAN M. E. (2003) Mixing patterns in networks, Physical Review E 67, 026126.

NOOTEBOOM B. (1999) Innovation, learning and industrial organisation, Cambridge Journal of Economics 23, 127-50.

NORTH D. (1990) Institutions, Institutional Change and Economic Performance. Cambridge University Press, Cambridge MA.

OBSTFELD D. (2005) Social networks, the Tertius iungens and orientation involvement in innovation, Administrative Science Quarterly 50, 100-30.

PECK J. and THEODORE N. (2007) Variegated capitalism, Progress in Human Geography 31, 731-72.

PEREZ C. (2009) The double bubble at the turn of the century: technological roots and structural implications, Cambridge Journal of Economics 33, 779-805. 
ROWLEY T., BEHRENS D. and KRACKHARDT D. (2000) Redundant governance structures: An analysis of structural and relational embeddedness in the steel and semiconductor industries, Strategic Management Journal 21, 369-86.

SAXENIAN A. (1994) Regional Advantage: Culture and Competition in Silicon Valley and Route 128. Harvard University Press MA, Cambridge.

SCHRÖDER M. and VOELZKOW H. (2016) Varieties of Regulation: How to Combine Sectoral, Regional and National Levels, Regional Studies 50, 7-19.

SNIJDERS T. A. (2001) The statistical evaluation of social network dynamics, in M S. and M B. (Eds) Sociological methodology, pp. 361-95. Basil Blackwell, Boston and London.

STORPER M. and VENABLES A. J. (2004) Buzz: face-to-face contact and the urban economy, Journal of Economic Geography 4, 351-70.

STORPER M. and WALKER R. (1989) The Capitalist Imperative: Territory, Technology, and Industrial Growth. Basil Blackwell, Cambridge MA.

SUAREZ F. F. (2004) Battles for technological dominance: an integrative framework, Research Policy 33, 271-86.

TEECE D. J., PISANO G. and SHUEN A. (1997) Dynamic capabilities and strategic management, Strategic Management Journal 18, 509-33.

TER WAL A. L. (2013a) Cluster emergence and network evolution: a longitudinal analysis of the inventor network in Sophia-Antipolis, Regional Studies 47, 651-68.

TER WAL A. L. J. (2013b) The dynamics of the inventor network in German biotechnology: geographic proximity versus triadic closure, Journal of Economic Geography doi:10.1093/jeg/lbs063, 1-32.

TER WAL A. L. J. and BOSCHMA R. A. (2011) Co-evolution of firms, industries and networks in space, Regional Studies 45, 919-33.

UZZI B. (1997) Social structure and competition in interfirm networks: The paradox of embeddedness, Administrative Science Quarterly 42, 35-67. 
WAGNER S. and COCKBURN I. (2010) Patents and the survival of Internet-related IPOs, Research Policy 39, 214-28.

WATTS D. J. (1999) Networks, dynamics, and the small-world phenomenon, American Journal of Sociology 105, 493-527.

WHITLEY R. (2006) Project-based firms: new organizational form or variations on a theme?, Industrial and Corporate Change 15, 77-99. 